\title{
Awareness of diabetic retinopathy among patients with type 2 diabetes mellitus in Jordan
}

\author{
May M Bakkar' \\ Mera F Haddad' \\ Yazan S Gammoh ${ }^{2}$ \\ 'Department of Allied Medical \\ Sciences, Faculty of Applied Medical \\ Sciences, Jordan University of \\ Science and Technology, Irbid, Jordan; \\ ${ }^{2}$ Department of Optometry, Faculty \\ of Pharmacy and Medical Sciences, \\ Al-Ahliyya Amman University, Amman, \\ Jordan
}

Correspondence: May M Bakkar Department of Allied Medical Sciences, Faculty of Applied Medical Sciences, Jordan University of Science and Technology, PO Box 3030, Irbid 221 10, Jordan Email bakkar.may@gmail.com
This article was published in the following Dove Press journal: Diabetes, Metabolic Syndrome and Obesity:Targets and Therapy II October 2017

Number of times this article has been viewed

Background: Increasing the level of awareness of diabetic retinopathy among individuals with type 2 diabetes mellitus is considered an important factor for early diagnosis and management of diabetic retinopathy. The aim of this study was to evaluate awareness of diabetic retinopathy among a sample of type 2 diabetes mellitus patients in Jordan.

Patients and methods: The study period was from August to December 2015. The sample was selected randomly from patients with type 2 diabetes mellitus from the general population in three main cities of Jordan (Amman, Irbid, and Zarqa). A questionnaire was distributed to 237 participants with diabetes to assess their awareness and knowledge of diabetes and diabetic retinopathy. The questionnaire included questions to assess awareness about diabetic retinopathy, sources of knowledge about the disease, and patients' knowledge and compliance with available treatments and routine eye examinations. Patients were also questioned about the barriers that may interfere with early eye examination.

Results: A total of 237 participants (107 [45.1\%] females and 130 [54.9\%] males) with type 2 diabetes were interviewed. Mean age \pm SD for the study population was $54.51 \pm 10.28$ years. Of the study population, $88.2 \%$ were aware that diabetes can affect the eyes and $81 \%$ reported that diabetic retinopathy can lead to blindness. Higher level of patients' awareness of diabetic retinopathy was related to higher level of formal education $(p<0.05)$. The main source of information about diabetic retinopathy as reported by $47.3 \%$ patients was general practitioners. Patients' compliance with diabetes management was relatively high; however, their compliance with routine retinal assessment was poor, with only a total of $29.5 \%$ of participants having had an eye examination in the previous year.

Conclusion: Awareness of the nature and consequences of diabetic retinopathy among patients with diabetes in Jordan is relatively high. However, patients' motivation to undergo retinal assessment was poor in the sample, thus hindering early diagnosis and management.

Keywords: awareness, compliance, diabetic retinopathy, diabetes mellitus, Jordan

\section{Background}

Diabetes mellitus (DM) is a metabolic disease characterized by alteration in carbohydrate, lipid and protein metabolism, where the body cannot regulate the amount of glucose in the blood. ${ }^{1}$ Based on various studies from different countries, the global prevalence of DM was reported to be $8 \%$ in 2011 and is expected to rise to $10 \%$ by 2030 . $^{2}$ The prevalence of DM is reported to be higher in Jordan than in other countries, with the reported prevalence being $17.1 \%$ in 2008 and this rate is expected to double in the next 10 years. ${ }^{3}$

DM can result in many complications such as nephropathy, cardiovascular, neurologic and ocular complications, ${ }^{4}$ with diabetic retinopathy (DR) being the most 
common microvascular ocular complication of DM. ${ }^{5} \mathrm{DR}$ is defined as a disorder of the retinal circulation that compromises the delivery of oxygen and nutrients to the retina, thus being unable to meet the requirements of its high metabolic demands. ${ }^{6}$ Therefore, defects in retinal circulation may affect normal vision, which is considered a leading cause of vision impairment and blindness worldwide. ${ }^{1,4,7}$ Many risk factors for DR have been reported among patients with diabetes; these include uncontrolled DM, longer periods of DM and the presence of other systemic diseases such as hypertension. ${ }^{8,9}$

Prevalence of DR among patients with DM varies worldwide. Many studies have reported the prevalence of DR in countries as follows: the USA $(28.5 \%),{ }^{10}$ the UK $(30.3 \%),{ }^{11}$ Australia (32.2\%), ${ }^{12}$ Japan $(39.6 \%)^{13}$ and Malaysia (39.3\%). ${ }^{14}$ Studies have also suggested many factors which may contribute to the variability in DR prevalence. These factors include race, patients' lifestyle, patients' access and adherence to available DM treatment and routine eye screening, and the health care system available in the country. ${ }^{9-14}$ In the Middle East region, there are a few reports on the prevalence of DR. Al-Till et al found that the prevalence of DR was $64.1 \%$ among Jordanian patients with DM. This value reported for the Jordanian population exceeded those reported for developed countries, ${ }^{15}$ probably due to the high prevalence of DM in the region. ${ }^{3}$

Increasing the level of awareness of DR as an ocular complication of DM among patients with diabetes is considered an important factor for early diagnosis and management of $\mathrm{DR}$, in addition to the prevention of possible visual impairment due to the disease. ${ }^{9}$ Variable levels of awareness of DR among patients with diabetes have been reported from different countries around the world. For example, in Australia, it was found that only $37 \%$ of the patients with diabetes were aware of the ocular complications of DM, ${ }^{16}$ and an even lower level of awareness (27\%) was found among patients with diabetes in India; ${ }^{17}$ in comparison, $65 \%$ of patients with diabetes in the USA were aware of DR. ${ }^{6}$

To date, there is a lack of studies that assess the awareness levels regarding DR among urban DM sufferers in Jordan. In view of the alarming increase in the incidence of DM in Jordan, this study was conducted to assess the awareness levels of DR, compliance with DM control and routine eye check-up among Jordanian type 2 DM patients.

\section{Patients and methods}

\section{Study design}

This cross-sectional study was conducted between August and December 2015. Participants were asked to answer questions in a structured questionnaire developed in Arabic, which included questions about awareness of DR due to DM and compliance with DM and DR management. All interviewed patients were with type $2 \mathrm{DM}$ and were randomly selected using multistage random cluster sampling from the general population in the three main cities in Jordan (Amman, Zarqa and Irbid). For each city, a random sample was then obtained from the general population of the city center of each city.

The required number of participants in the study depended on the percentage of Jordanians with DM. For DM prevalence from $10 \%$ to $17 \%$ (based on the literature), given that the number of Jordanians is about 6 million, complete data from 139 to 217 participants would be needed. Using http://www.raosoft.com/samplesize.html, allowed the percentage of correct answers to be estimated with a $95 \% \mathrm{CI}$ and a margin of error of at the most $\pm 2 \%$. So, 237 participants were considered to be adequate.

The content validity of the questionnaire was assessed by an expert panel of four anonymous specialists of advanced medical background who have been working in the Jordanian health sector for a long period of time. Prior to the study, for the assessment of the reliability of the questionnaire, a random sample of 36 patients with diabetes was recruited to complete the questionnaire and the obtained Cronbach's alpha value was 0.8 . Based on the preliminary results which showed a redundancy in some questions, the questionnaire was amended and these results were disregarded in the final data analysis.

\section{Inclusion criteria}

Only the participants with type 2 DM who had normal cognitive ability and could speak Arabic as a first language were recruited in the study.

\section{Data collection}

Patients were asked to answer a questionnaire which included 24 questions divided into three main sections:

1. basic sociodemographic information that included age, gender, educational level, family history of DM and duration of DM;

2. knowledge about diabetes, DR and source(s) of knowledge; a sample of the questions related to this section is shown in Table 1; and

3. patient's compliance with DM control, treatment and routine eye check-up visits.

Finally, patients were asked about the possible barriers which they might have experienced and subsequently 
Table I Questions related to awareness of DR related to DM

1. Are you aware that DM can affect the retina of the eye? Yes/No

2. Are you aware that DR can lead to blindness? Yes/No

3. Do you think that blood sugar control may reduce the risk of DR? Yes/No

4. Do you think that routine eye check-ups are necessary during DM? Yes/No

5 . How frequently do you think you should undergo an eye check-up?

Every 6 months/yearly/2 yearly/only when vision is affected

6. Do you know that laser treatment for DR does not improve vision but reduce further deterioration in vision? Yes/No

7. What are your sources of information about DM and DR?

The Internet, magazines/doctor/friends and relatives/ or I do not get any information

Abbreviations: DM, diabetes mellitus; DR, diabetic retinopathy.

prevented them from doing early eye check-up examinations after they had been diagnosed with DM.

All procedures performed in the study were in accordance with the ethical standards of the institutional research committee, and the ethics approval for conducting this study was granted by the Institutional Review Board committee at Jordan University of Science and Technology. The study has been conducted in accordance with the Declaration of Helsinki of 1975 and its later amendments.

Informed consent was obtained from all individual participants included in the study prior to their participation in the study.

\section{Data analysis}

Data were analyzed using the SPSS software version 20 (IBM Corporation, Armonk, NY, USA).

Numbers and percentages were calculated to summarize categorical and nominal data. For categorical outcomes, the chi-square test $\left(\chi^{2}\right)$ was used for univariate analysis and for finding significant differences in participants' characteristics. The level of significance was set at $p<0.05$.

\section{Results}

\section{Characteristics of patients}

A total of 237 patients (107 females, 130 males) participated in the study. The average age ( $\pm \mathrm{SD})$ of the study group was $54.51 \pm 10.28$ years and it ranged from 25 to 80 years. All patients were diagnosed with type $2 \mathrm{DM}$. Of the study sample, $102(43 \%)$ were diagnosed with the disease for $<5$ years, 78 (32.9\%) between 6 and 10 years and 57 (24.1\%) for more than 11 years. The characteristics of all participants are shown in Table 2.

\section{Knowledge and awareness of DR}

Data obtained show that out of the 237 interviewed participants, $209(88.2 \%)$ were aware that DM can affect the retina through DR and 194 (81.9\%) patients reported that DR can
Table 2 Demographic characteristics of study population $(\mathrm{N}=237)$

\begin{tabular}{|c|c|}
\hline Variable & \\
\hline Age, years (mean $\pm S D)$ & $54.51 \pm 10.283$ \\
\hline \multicolumn{2}{|l|}{ Gender } \\
\hline Female, n (\%) & $107(45.1)$ \\
\hline Male, n (\%) & $130(54.9)$ \\
\hline \multicolumn{2}{|l|}{ Education, n (\%) } \\
\hline None & $28(11.8)$ \\
\hline Elementary school & $46(19.4)$ \\
\hline High school & $83(35.0)$ \\
\hline Higher education & $80(33.8)$ \\
\hline \multicolumn{2}{|l|}{ Duration of DM, n (\%) } \\
\hline$\leq 5$ years & $102(43)$ \\
\hline $6-10$ years & $78(32.9)$ \\
\hline$\geq I I$ years & $57(24.1)$ \\
\hline \multicolumn{2}{|l|}{ Family history of DM, n (\%) } \\
\hline Yes & 174 (73.4) \\
\hline No & $63(26.6)$ \\
\hline \multicolumn{2}{|l|}{ Blood glucose control, n (\%) } \\
\hline Yes (good) & $188(79.3)$ \\
\hline No (bad) & $49(20.7)$ \\
\hline \multicolumn{2}{|c|}{ Source of information about DM, n (\%) } \\
\hline Doctor & I I 2 (47.3) \\
\hline Relatives/friends & $76(32)$ \\
\hline Mass media & $35(14.8)$ \\
\hline Not received any information & $14(5.9)$ \\
\hline \multicolumn{2}{|l|}{ Referral to eye doctor, n (\%) } \\
\hline General practitioner & $|4|(59.5)$ \\
\hline Patient himself & $91(38.4)$ \\
\hline Have no referral yet & $5(2.1)$ \\
\hline \multicolumn{2}{|l|}{ If vision is affected by DM } \\
\hline Yes & $134(56.5)$ \\
\hline No & $103(43.5)$ \\
\hline
\end{tabular}

Abbreviation: DM, diabetes mellitus.

lead to blindness. Figure 1 shows the percentages of patients who answered different questions related to awareness of DR.

In regards to awareness of DR control and treatment, 196 patients $(82.7 \%)$ were aware that blood glucose level control can reduce the risk of DR development. However, only 91 patients (38.4\%) were aware that laser treatment can be used to control the prognosis of DR. 
When patients were asked about their knowledge on how often the eyes should be examined during diabetes, a total of 120 participants $(50.6 \%)$ answered "every 6 months", 49 patients $(20.7 \%)$ thought that eye examinations should be done every year and 12 patients (5.1\%) answered "every 2 years". The response of 56 patients $(23.6 \%)$ was that retinal assessment is important only when vision is affected.

\section{Main source of information about DR}

In this study, $94.1 \%$ of the patients responded that they had received information about $\mathrm{DM}$, while only $5.9 \%$ reported that they had not received any information about the disease and its complications (Table 2).

General practitioners were the main source of information regarding DM and DR for 112 (47.3\%) participants, while 76 (32\%) subjects obtained their information from relatives and friends affected by diabetes. Media such as Internet, TV, magazines and newspapers were the main source of information for 35 participants (14.8\%). Only 14 participants (5.9\%) reported that they had not received any information about DM and its complications including DR.

\section{Analysis of association between awareness of DR and selected variables (gender, age, family history, duration of DM, blood sugar control, educational level)}

Univariate analysis showed that awareness of DR was not significantly associated with patients' gender $(p=0.479)$, age $(p=0.78)$ and family history of DM $(p=0.177)$.
Of the study population, 188 patients (79.3\%) reported upon questioning that they had good blood sugar control. However, this also did not have a statistically significant effect on the awareness level of DR $(p=0.269)$.

Remarkably, the level of awareness of DR was found to be significantly associated with patients' educational level $(p=0.003)$, as shown in Table 3 . Patients with a relatively higher educational level (secondary education, graduates and post-graduates) were more aware of DR occurring as a consequence of diabetes.

Table 3 Univariate analysis for association between awareness of DR and selected variables

\begin{tabular}{|c|c|c|c|}
\hline Variable & Aware, n (\%) & OR (95\% Cl) & $p$-value \\
\hline \multicolumn{4}{|l|}{ Gender } \\
\hline Male & II4 (87.7) & 0.9 & 0.795 \\
\hline Female & $95(88.8)$ & $(0.406-1.996)$ & \\
\hline \multicolumn{4}{|l|}{ Education } \\
\hline None & $20(70.4)$ & 4.86 & $0.003^{*}$ \\
\hline Elementary school & $40(86.7)$ & $(I .42 I-16.633)$ & \\
\hline High school & $72(86.7)$ & & \\
\hline More than high school & $77(96.2)$ & & \\
\hline \multicolumn{4}{|l|}{ Duration of DM } \\
\hline$\leq 5$ years & $90(88.2)$ & 0.766 & 0.792 \\
\hline $6-10$ years & 70 (89.7) & $(0.318-1.846)$ & \\
\hline$\geq 1 \mathrm{I}$ years & $49(87.5)$ & & \\
\hline \multicolumn{4}{|l|}{ Family history of DM } \\
\hline Yes & $156(89.7)$ & 1.625 & 0.25 \\
\hline No & $53(84.1)$ & $(0.706-3.739)$ & \\
\hline \multicolumn{4}{|l|}{ Blood glucose control } \\
\hline Good & $165(87.2)$ & 0.607 & 0.374 \\
\hline Bad & $45(91)$ & $(0.2-1.84 I)$ & \\
\hline
\end{tabular}

Note: *Statistical significance based on non-overlapping $95 \%$ confidence intervals. Abbreviations: DM, diabetes mellitus; DR, diabetic retinopathy; OR, odds ratio.

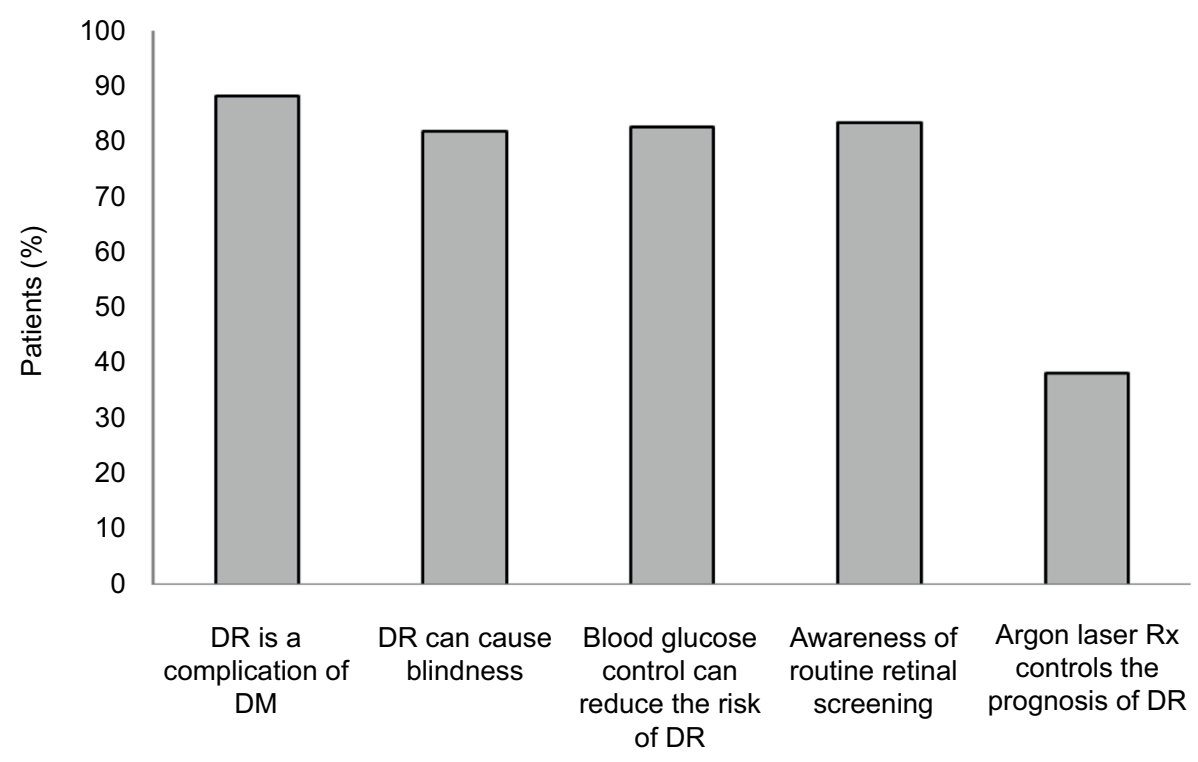

Figure I Percentages of patients who answered different awareness questions related to DR. Abbreviations: DM, diabetes mellitus; DR, diabetic retinopathy. 


\section{Patients' compliance with available treatments and routine eye examination}

Most patients (87.8\%) were adherent to treatment of DM, and $69.6 \%$ reported measuring blood sugar at home. However, the frequency of measuring the level of blood sugar was low, with the majority (24.9\%) performing the test only when feeling unwell. Regarding the frequency of eye examinations, although $37.6 \%$ of the patients had an eye exam in the past 6 months at the time of study, almost an equivalent percentage (32.9\%) of the patients had never tested their eyes since they were diagnosed with DM. Table 4 shows the results of patients' compliance with DM treatment and eye examinations for the subsections of patients who were aware of DR and those patients who were not aware of DR.

\section{Patients' related barriers for early retinal assessment}

Regarding their motivation for doing retinal assessment, 141 patients $(59.5 \%)$ were referred for retinal assessment by an eye doctor and 91 patients (38.4\%) answered that they had done the test due to self-awareness of DM ocular complications. Finally, only five patients $(2.1 \%)$ reported that they did not have any referral yet for retinal assessment (Table 2).

The responses obtained from the participants when they were questioned about the possible barriers for not getting early retinal assessment are shown in Figure 2.

\section{Discussion}

The lack of awareness about DR is considered a major health problem that could interfere with proper management and

Table 4 Compliance behaviors with available DM and DR management among patients

\begin{tabular}{llll}
\hline Compliance behaviors & Aware, $\mathbf{n}(\%)$ & Not-aware, $\mathbf{n}(\%)$ & $\mathbf{n}(\%)$ \\
\hline $\begin{array}{l}\text { Adherence to current DM treatment } \\
\text { Yes }\end{array}$ & $181(86.6)$ & $27(96.4)$ & $208(87.8)$ \\
No & $28(13.4)$ & $1(3.6)$ & $29(12.2)$ \\
Measuring blood sugar at home & & & \\
Yes & $146(69.9)$ & $19(67.9)$ & $165(69.6)$ \\
No & $63(30.1)$ & $9(32.1)$ & $72(30.4)$ \\
Frequency of measuring blood sugar at home & $26(12.4)$ & & 0.217 \\
Every month & $40(19.1)$ & $3(10.7)$ & $29(12.2)$ \\
Every week & $29(13.9)$ & $7(25)$ & $47(19.8)$ \\
Everyday & $55(26.3)$ & $5(17.9)$ & $34(14.3)$ \\
Once I feel unwell & $59(28.2)$ & $4(14.3)$ & $59(24.9)$ \\
Never & $9(32.1)$ & $68(28.7)$ \\
Last vision exam & $76(36.4)$ & & 0.892 \\
During the last 6 months & $63(30.1)$ & $13(46.4)$ & $89(37.6)$ \\
During the last year & $70(33.5)$ & $7(25)$ & $70(29.5)$ \\
Never & $8(28.6)$ & $78(32.9)$ \\
\hline
\end{tabular}

Abbreviations: DM, diabetes mellitus; DR, diabetic retinopathy.

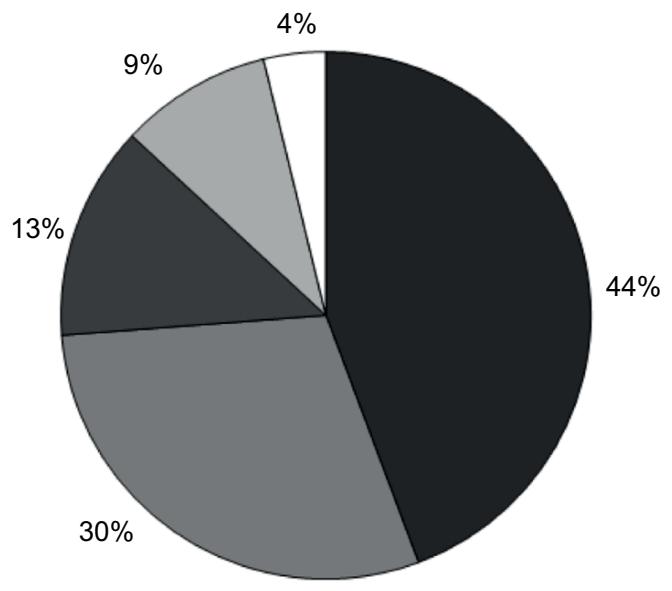

Lack of information about DR

Lack of time

Cost of test

Fear of discovering

something bad

Living in remote area

Figure 2 Patients' related barriers for early retinal assessment. Abbreviation: $D R$, diabetic retinopathy. 
prevention of possible visual impairment. There seems to be a worldwide trend of a lack of awareness of DM in the population. The aim of our study was to report the levels of awareness of DR among patients with type 2 diabetes.

The prevalence of DR among patients with diabetes in Jordan was reported to be $64.1 \%$, which was higher than that reported in most regional and international studies. ${ }^{18}$ It has also been shown that visual impairment and blindness due to diabetes were prevalent among Jordanian adults. ${ }^{15}$ These findings are of interest to our study, as the results of this study showed high awareness of DR occurring as a complication of DM among Jordanians with diabetes, which is contrary to the high prevalence of DR in Jordan. Furthermore, the level of awareness of DR reported in our study is much higher than the levels reported in other places such as Turkey ${ }^{19}$ and Baltimore, USA. ${ }^{20}$

In Jordan, there is an established national eye health care program and referral guidelines regarding DM and DR management for primary care. Patients are referred for an eye examination at the same time as their diagnosis of DM. This may explain the high level of awareness of DR found in this study.

The main factor that was related to increased awareness of DR in the study was the level of education. It has been previously shown in Jordan that higher levels of education are associated with higher awareness of DM. ${ }^{21}$ This is consistent with several reports from other countries that show patients with higher education levels are more aware and well informed about DR occurring as a complication of DM, compared to patients with low levels of education. ${ }^{19,22-23}$

The main source of information about DR in our sample was general practitioners, followed by relatives and mass media. This is consistent with the reported sources of information about DM among Jordanians. ${ }^{21}$ This result is consistent with other reports; for example, a study from Pakistan showed that doctors were the major source of information about DR. ${ }^{22}$

Despite the high level of awareness about DR in the study, the level of patients' compliance with behaviors to reduce the risk of DR was low. The majority of the study cohort reported that they should have routine eye examination every 6 months or every year. Despite this knowledge displayed by the cohort, there was a low compliance in attending eye examinations. Such a discrepancy between the levels of awareness and compliance in terms of routine eye examination seems to be common among patients with diabetes in the world, with reports stating that only half of the patients in Myanmar ${ }^{23}$ and two-thirds of Japanese patients attended a routine eye examination, ${ }^{24}$ and a recent study in Turkey showed that while $41.9 \%$ of patients with diabetes were aware of annual eye examination, $77.3 \%$ of these patients previously had an eye examination. ${ }^{19}$

The reason given by patients for not getting an early DR screening was mainly a lack of information about DR. Other reported reasons included a lack of time to take the examination, cost of the test and a fear of discovering bad things about their eyes. This finding warrants further investigation into how to encourage patients with diabetes to routinely comply with vision examinations and retinal assessments every 12 months, as recommended by the international guidelines. ${ }^{25}$

Of interest regarding the issue of eye examinations, our results show that only $59.5 \%$ of the patients interviewed were referred to an ophthalmologist by their general practitioner, with the rest of the patients reporting either self-referral or no referral to ophthalmologists. This calls for a general strategy of mandatory referrals to ophthalmologists to be adopted by general practitioners in Jordan.

Considering the fact that DR complications become more severe with prolonged duration of diabetes, it is imperative that spreading awareness on DR should be adopted by the practitioners at early stages of DM. Furthermore, public health awareness campaigns need to follow well-planned strategies. As part of the community may not be able to pursue higher education, school programs need to be revised to increase awareness of noncommunicable diseases such as DM.

To the best of our knowledge, this is the first Jordanian study on awareness of patients with diabetes with regard to $\mathrm{DR}$ as a possible complication of diabetes. The significance of such studies in community health planning becomes more evident in light of the fact that DR is one of the main causes of blindness and vision impairment globally.

\section{Conclusion}

In this study, a sample of patients with type $2 \mathrm{DM}$ was recruited to assess their awareness level of DR. While the majority of patients reported high levels of awareness, most of the patients with diabetes were not compliant with DM management guidelines in regards to reducing the risk of DR. Level of education was the main factor found to be significantly associated with awareness of DR.

There is an imperative need to implement strategies to increase the awareness of DR and the importance of early retinal screening among affected patients, in order to reduce the risk of visual complications. Additionally, screening 
programs for DR should not be exclusive to eye care centers, and in order to access undiagnosed patients, it is recommended to implement screening campaigns close to their place of residence. Other causes of poor compliance with follow-up and available treatment should be studied further.

\section{Acknowledgments}

This study was supported by the Deanship of Research at Jordan University of Science and Technology. We would like to thank Dr Mohammad AlQadire (Al Al-Bayt University) for his help in statistical analysis of the results. We would like to thank all participants who agreed to participate in this study.

\section{Disclosure}

The authors report no conflicts of interest in this work.

\section{References}

1. Olokoba AB, Obateru OA, Olokoba LB. Type 2 diabetes mellitus: a review of current trends. Oman Med J. 2012;27(4):269-273.

2. Guariguata L, Whiting DR, Hambleton I, Beagley J, Linnenkamp U, Shaw JE. Global estimates of diabetes prevalence for 2013 and projections for 2035. Diabetes Res Clin Pract. 2014;103(2):137-149.

3. Ajlouni K, KhaderYS, Batieha A, Ajlouni H, El-Khateeb M. An increase in prevalence of diabetes mellitus in Jordan over 10 years. $J$ Diabetes Complications. 2008;22(5):317-324.

4. Alberti KG, Zimmet PZ. Definition, diagnosis and classification of diabetes mellitus and its complications. Part 1: diagnosis and classification of diabetes mellitus provisional report of a WHO consultation. Diabet Med. 1998;15(7):539-553.

5. Nsiah-Kumi P, Ortmeier SR, Brown AE. Disparities in diabetic retinopathy screening and disease for racial and ethnic minority populations - a literature review. J Natl Med Assoc. 2009;101(5):430-437.

6. Tajunisah I, Wong P, Tan L, Rokiah P, Reddy S. Awareness of eye complications and prevalence of retinopathy in the first visit to eye clinic among type 2 diabetic patients. Int J Ophthalmol. 2011;4(5):519-524.

7. Wong TY, Cheung N, Tay WT, et al. Prevalence and risk factors for diabetic retinopathy: the Singapore Malay Eye Study. Ophthalmology. 2008;115(11):1869-1875.

8. Chatziralli IP, Sergentanis TN, Keryttopoulos P, Vatkalis N, Agorastos A, Papazisis L. Risk factors associated with diabetic retinopathy in patients with diabetes mellitus type 2. BMC Res Notes. 2010;3:153.

9. Liu L, Wu J, Yue S, et al. Incidence density and risk factors of diabetic retinopathy within type 2 diabetes: a five-year cohort study in China (Report 1). Int J Environ Res Public Health. 2015;12(7):7899-7909.
10. Zhang $X$, Saaddine JB, Chou CF, et al. Prevalence of diabetic retinopathy in the United States, 2005-2008. JAMA. 2010;304(6):649-656.

11. Kostev K, Rathmann W. Diabetic retinopathy at diagnosis of type 2 diabetes in the UK: a database analysis. Diabetologia. 2013;56(1):109-111.

12. Jaross N, Ryan P, Newland H. Prevalence of diabetic retinopathy in an Aboriginal Australian population: results from the Katherine Region Diabetic Retinopathy Study (KRDRS). Report no. 1. Clin Exp Ophthalmol. 2003;31(1):32-39.

13. Kawasaki R, Tanaka S, Yamamoto T, et al. Incidence and progression of diabetic retinopathy in Japanese adults with type 2 diabetes: 8 year follow-up study of the Japan Diabetes Complications Study (JDCS). Diabetologia. 2011;54(9):2288-2294.

14. Abougalambou SS, Abougalambou AS. Risk factors associated with diabetic retinopathy among type 2 diabetes patients at teaching hospital in Malaysia. Diabetes Metab Syndr. 2015;9(2):98-103.

15. Al-Till MI, Al-Bdour MD, Ajlouni KM. Prevalence of blindness and visual impairment among Jordanian diabetics. Eur J Ophthalmol. 2005; 15(1):62-68.

16. Livingston PM, Wood CA, McCarty CA, Harper CA, Keeffe JE, Taylor HR. Awareness of diabetic retinopathy among people who attended a diabetic retinopathy screening program. Med J Aust. 1998; 169(2):117.

17. Hussain R, Rajesh B, Giridhar A, et al. Knowledge and awareness about diabetes mellitus and diabetic retinopathy in suburban population of a South Indian state and its practice among the patients with diabetes mellitus: A population-based study. Indian J Ophthalmol. 2016;64(4): $272-276$.

18. Al-Bdour MD, Al-Till MI, Abu Samra KM. Risk Factors for Diabetic Retinopathy among Jordanian Diabetics. Middle East Afr J Ophthalmol. 2008; $15(2): 77-80$

19. Cetin EN, Zencir M, Fenkci S, Akin F, Yildirim C. Assessment of awareness of diabetic retinopathy and utilization of eye care services among Turkish diabetic patients. Prim Care Diabetes. 2013;7(4):297-302.

20. Munoz B, O'Leary M, Fonseca-Becker F, et al. Knowledge of diabetic eye disease and vision care guidelines among Hispanic individuals in Baltimore with and without diabetes. Arch Ophthalmol. 2008;126(7):968-974.

21. Al-Khawaldeh OA, Al-Jaradeen N. Diabetes awareness and diabetes risk reduction behaviors among attendance of primary healthcare centers Diabetes Metab Syndr. 2013;7(3):172-178.

22. Masood I, Saleem A, Hassan A, Umm EK, Zia A, Khan AT. Evaluation of diabetes awareness among general population of Bahawalpur, Pakistan. Prim Care Diabetes. 2016;10(1):3-9.

23. Muecke JS, Newland HS, Ryan P, et al. Awareness of diabetic eye disease among general practitioners and diabetic patients in Yangon, Myanmar. Clin Experiment Ophthalmol. 2008;36(3):265-273.

24. Fukushima H, Kato S. [Diabetic retinopathy]. Nihon Rinsho. 2015;73(12):2032-2036. Japanese.

25. Nentwich MM, Ulbig MW. Diabetic retinopathy - ocular complications of diabetes mellitus. World J Diabetes. 2015;6(3):489-499.

Diabetes, Metabolic Syndrome and Obesity: Targets and Therapy

\section{Publish your work in this journal}

Diabetes, Metabolic Syndrome and Obesity: Targets and Therapy is an international, peer-reviewed open-access journal committed to the rapid publication of the latest laboratory and clinical findings in the fields of diabetes, metabolic syndrome and obesity research. Original research, review, case reports, hypothesis formation, expert
Dovepress

opinion and commentaries are all considered for publication. The manuscript management system is completely online and includes a very quick and fair peer-review system, which is all easy to use. Visit http://www.dovepress.com/testimonials.php to read real quotes from published authors. 